\title{
Infección de vías urinarias en niños menores de 12 años en zona Rural de Chontales-Nicaragua
}

Yuber Ariel Lazo Guerrero ${ }^{1}$

\section{INFORMACIÓN DEL ARTÍCULO}

Recibido: 30.04 .2020

Aprobado: 30.05 .2020

\section{Palabras claves:}

Diagnóstico,

Escherichia,

Coli,

Infección Urinaria,

Urocultivo

\section{RESUMEN}

El objetivo del presente trabajo es determinar mediante pruebas diagnósticas la presencia de infección de vías urinarias en niños menores de 12 años en la comunidad en estudio "San Marcos" que se encuentra a $24 \mathrm{Km}$ de Juigalpa Chontales, está estimado que cuenta con 45 viviendas siendo un total de 38 niños como población de estudio, los cuales cumplen con criterios de inclusión para esta investigación. En los niños la ITU se puede agrupar como un primer episodio, usualmente benigna, o como ITU recurrente, que puede llevar a daño glomerular y formación de cicatrices renales. Del 10 al 30 \% de los pacientes presentan complicaciones, como hipertensión arterial (HTA), proteinuria e insuficiencia renal crónica. Los niños con alto riesgo de desarrollar cicatrices renales deben ser identificados precozmente con medidas diagnósticas para un adecuado tratamiento. Se trata de una investigación cuantitativa sustentada en un diseño descriptivo con participación de niños menores de 12 años que viven en esta comarca. El universo fue de 38 niños con criterios de inclusión respecto a las edades, por lo que la muestra estuvo constituida por 30 niños del total de la población en estudio. Del 100\% de las muestras analizadas el 10\% de ellas presentaron alteraciones celulares que orientan a una ivu en el Examen general de orina con predominio de afección en el sexo femenino en edades de 4 -5 años. Se aisló en el 10\% de ellos la bacteria Escherichia coli con el medio diagnostico Urocultivo.

\section{Urinary tract infection in children under 12 years old in rural areas from Chontales-Nicaragua}

\begin{abstract}
The objective of this work is to determine through diagnostic tests the presence of urinary tract infection in children under 12 years old in the village called "San Marcos" located at $24 \mathrm{~km}$ from Juigalpa Chontales. It is estimated that it has 45 homes where 38 children are taken as the study population. In addition, they meet the inclusion criteria for this research. In those children, the UTI can be grouped as a first episode. It is usually benign, or as recurrent UTI, which can cause

\footnotetext{
1 Doctor en Salud Publica. Profesor de la Universidad Nacional Autónoma de Nicaragua, Managua - Facultad Regional
} Multidisciplinaria - Chontales. Email: yuberlazo.guerrero@gmail.com (D): https://orcid.org/oooo-0003-4774-7083
\end{abstract}


glomerular damage and kidney scar formation. From 10 to $30 \%$ of patients present complications, such as hypertension (HT), proteinuria and chronic renal failure. Children with high risk of developing kidney scars should be identified early with diagnostic measures for a proper treatment. It is a quantitative research supported by a descriptive design with the participation of children under 12 years old who live in that village. The universe was 38 children with inclusion criteria regarding the age, so the sample consisted of 30 children from the total study population. From the $100 \%$ of the analyzed samples, $10 \%$ of them presented cellular alterations that lead to an IVU in the General Urine Examination with predominance of affection in female sex from 4-5 years old. Escherichia coli bacteria were isolated in $10 \%$ of them with the urine culture diagnostic tool.

\section{Introducción}

La infección del tracto urinario (ITU) es una de las infecciones más frecuentes en Pediatría, y representa cerca de un millón de consultas anuales a los servicios de urgencias en los Estados Unidos. Es reconocida como una causa de enfermedad aguda y crónica de gran morbilidad (Avila \& Espinoza, 2008). En los niños la ITU se puede agrupar como un primer episodio, usualmente benigna, o como ITU recurrente, que puede llevar a daño glomerular y formación de cicatrices renales. Del 10 al $30 \%$ de los pacientes presentan complicaciones, como hipertensión arterial (HTA), proteinuria e insuficiencia renal crónica. Los niños con alto riesgo de desarrollar cicatrices renales deben ser identificados precozmente con medidas diagnósticas para un adecuado tratamiento (Alvarez, 2013). Las infecciones del tracto urinario es la enfermedad bacteriana, de carácter no epidémico, más frecuente en la infancia. Aproximadamente entre 3 a 5\% de las mujeres y entre 1-2\% de los varones se verán afectados a lo largo de su infancia al menos un episodio (Cruz, 2007). Según datos del Ministerio de Salud de Nicaragua (2009), la infección del tracto urinario es un problema frecuente en la población pediátrica.

En este contexto, se presenta una investigación sobre la infección de vías urinarias en niños menores de 12 años en zona rural del departamento de Chontales, Nicaragua. Se trata de una investigación cuantitativa que toma en consideración factores asociados a las IVU en los niños de estas edades.

\section{Literatura}

La infección del tracto urinario (ITU) es una de las infecciones bacterianas más frecuentes en pediatría, ya que el 8-10\% de las niñas y el 2-3\% de los niños tendrán una ITU sintomática antes de los siete años de edad, siendo más frecuente en varones en los primeros tres meses de vida y produciéndose un incremento progresivo con predominio de niñas a partir del año de vida, con alta probabilidad de recurrencia (>30\%) por reinfecciones distintos a la primera manifestación especialmente durante el primer año tras el episodio inicial (Gonzalez \& Rodriguez, 2014). 
Su incidencia mayor es en el periodo de la lactancia. Siendo una de las patologías nefro-urológica más frecuente a la que se tiene que enfrentar el Pediatra de la atención primaria. Genera una alta morbilidad durante la fase aguda con repetidas visitas al médico, precisando de uno o varios esquemas de tratamiento antibiótico, siendo necesario la hospitalización en múltiples ocasiones (Cruz, 2007). En el año 1884, Escherich, pediatra alemán, identificó la bacteria que hoy lleva su nombre en la flora fecal del lactante y en 1894 demostró su presencia en la orina de estos pacientes (Cruz, 2007).

La infección urinaria es la presencia de bacteriuria significativa sintomática o no, teniendo en cuenta que el riñón y la orina en la vejiga son normalmente estériles y que en la parte externa de la uretra en la mujer y en menor grado en el varón es detectable una colonización bacteriana que se define como la multiplicación de gérmenes sin aparente evidencia de invasión o daño del tejido.

La infección del tracto urinario (ITU) es definida como la colonización, invasión y multiplicación en la vía urinaria de microorganismos patógenos especialmente bacterias, que habitualmente provienen de la región perineal (vía ascendente) si bien existe la posibilidad muy infrecuente de infección por vía sistémica (vía hematógena) o directa (cirugías urológicas, traumas, abdominales). Tradicionalmente las infecciones del tracto urinario han sido clasificadas:

- Por el sitio de infección: en infecciones urinarias altas como pielonefritis (riñón)

- Infecciones urinarias bajas como cistitis (vejiga), uretritis ( uretra) (Cruz, Saballos, \& Gurachi, 2007)

En nuestro medio es difícil determinar exactamente la incidencia de la IVU, pues no existe al momento ningún estudio de prevalencia de esta, hasta el momento actual hay dificultades en la técnica de recolección de la muestra por parte de los padres de familia, lo que genera como resultado falsas bacteriurias y criterios no establecidos de hospitalización y tratamiento.

Por ello se decidió acoger un tema de tanta relevancia, con la finalidad de aportar a la comunidad un estudio que permita conocer el porcentaje de niños con IVU y la relevancia que tienen los método de diagnóstico como el Examen General de Orina y el urocultivo,los resultados de esta investigación servirán de base de datos para un precoz y oportuno tratamiento con la finalidad de evitar las secuelas nefrológicas de las mismas, siendo las infecciones de vías urinarias en niños un problema de salud Publica.

\subsection{Diagnóstico}

Según la Sociedad Española de Enfermedades Infecciosas y Microbiología Clínica (SEIMC), la infección urinaria asintomática o bacteriuria asintomática (BA) se define 
por la presencia en orina de $\geq 100.000 \mathrm{UFC} / \mathrm{mL}$ con o sin piuria, en ausencia de síntomas de ITU. En mujeres, para confirmar el diagnóstico, se requiere el aislamiento del mismo uropatógeno en dos muestras de orina obtenidas con un intervalo de unas dos semanas. Entre $10 \%$ y $60 \%$ de mujeres no tienen bacteriuria persistente y el resultado de la segunda muestra es negativo.

Leucocitos (Piuria). Se consideran normales recuentos de hasta 5 leucocitos/ campo. Cifras mayores indican la existencia de un proceso inflamatorio o infeccioso en riñón o vías urinarias. La infección urinaria puede manifestarse con presencia de piuria y bacteriuria. Sin embargo, existe la denominada piuria estéril (piuria sin bacteriuria) que puede tener un origen infeccioso (tuberculosis urogenital, infección urinaria por bacterias exigentes o de crecimiento lento) o deberse a otros procesos (cálculos, tumores, traumatismos). Estos leucocitos también ser de procedencia vaginal o uretral (Navarra, 2002).

La realización de un análisis de orina exacto comienza con una adecuada técnica de recolección. Existen diversos métodos utilizables dependiendo del tipo de muestra necesaria. Existen dos formas de recolectar muestras de orina en niños, la micción espontánea y las bolsas recolectoras, que se usan cuando aún no hay control de esfínteres. En ambos casos se debe realizar un buen aseo genital con agua, sin jabón, ni antisépticos. El primer paso es utilizar un embace limpio y seco. la mayoría de los laboratorios prefieren los envases descartables ya que de este modo se evita la posibilidad de contaminación por lavado inadecuado de los frascos de recolección (Strasinger, Di Lorenzo\& King,2010).

Con el objetivo de obtener muestras adecuadas en lactantes y en niños de corta edad se dispone de colectores pediátricos que se fijan a los genitales. Son blandos y plegables y no causan demasiada incomodidad al paciente. No obstante, como en todos los casos de recolección de orina, se debe tratar de evitar la contaminación fecal (Graff, 1987).

Una vez recolectada, la muestra de orina debe ser analizada en forma inmediata y si esto no es posible se debe refrigerar a $4^{\circ} \mathrm{C}$ hasta el procesamiento en el laboratorio (por un período máximo de 24 horas). En niños que controlan esfínteres, se solicita recabar la muestra del segundo chorro de orina. En lactantes y recién nacidos la muestra debe obtenerse por cateterismo o punción vesical (Carrera \& Andrade, 2014).

De los componentes del uro análisis, los más valiosos para la evaluación de una posible IVU son la prueba de esterasa leucocitaria positiva, presencia de nitritos y la valoración microscópica del sedimento urinario. Cualquiera de los siguientes hallazgos: esterasa leucocitaria, nitritos positivos, más de cinco leucocitos por campo o Tinción de Gram positiva, son sugerentes de IVU. Un resultado negativo en estas pruebas no descarta infección pues todas tienen falsos negativos entre $17 \%$ y $47 \%$. 
La esterasa es la prueba más sensible, sin embargo, su especificidad no es buena; los nitritos, indicadores indirectos de bacteriuria, tienen una especificidad muy alta pero la más baja sensibilidad; por ello pueden ser útiles para confirmar IVU cuando son positivos, pero un resultado negativo tiene poco valor para excluir la infección (Carrera \& Andrade, 2014).

\begin{tabular}{|c|c|c|}
\hline Analito & Sensibilidad \% & Especificidad \% \\
\hline Nitritos positivos & 53 & 98 \\
\hline Leucocitos* & 73 & 81 \\
\hline Bacterias & 81 & 83 \\
\hline
\end{tabular}

\subsection{Métodos Diagnósticos utilizados en el estudio}

La tinción de Gram, es una técnica de aislamiento bacteriológico descubierta en 1884, por Christian Gram a quien debe su nombre. Describe la morfología celular clasificando las bacterias en Gram positivas las que se tiñen de color morado y Gram negativas las que tiñen de color rosado o rojo. El procedimiento es sencillo, una vez recogida la muestra, se coloca una gota de orina en la placa portaobjetos, se seca flameando con el mechero, se enjuaga con agua y se agrega cristal violeta, se enjuaga nuevamente con agua y se fija con lugol, se lava con agua y se aplica alcohol al 100\% o alcohol-cetona, se fija por 30 segundos y se aplica colorante safranina, y se observa los resultados de la tinción (Díaz, Gamazo y López,1999).

Se recomienda realizar una tinción de Gram cuando se necesite hacer un aislamiento y clasificación bacteriana en forma rápida y sencilla, estos parámetros lo constituyen en una herramienta rutinaria como parámetro de orientación clínica, pues presenta ventajas costo beneficio y sirve de tamizaje para el diagnóstico de certeza de IVU (infección de vías urinarias). La sensibilidad de la tinción de Gram se calcula en 65\%, y su especificidad en 94\%. y para el Urocultivo se ha encontrado una sensibilidad del $75 \%$ y especificidad del $98 \%$. Se concluye entonces que ambos métodos son de similar utilidad diagnóstica, pero el resultado del urocultivo requiere mayor tiempo y costo (Carrera \& Andrade, 2014).

Otro método es el examen microscópico de orina es una práctica previa al cultivo que puede revelar importante información a la hora de hacer una interpretación o tomar la decisión de concluir el diagnostico, sin embargo, este debe de tener recomendaciones para su colección. Una muestra al Azar es por lo general suficiente para la realización de la mayoría de las pruebas selectivas; pero como la primera micción matinal es más concentrada, resulta por lo general la muestra de elección. Las muestras recolectadas al Azar durante el día a veces presentan dilución, por un aumento 
en el consumo de líquidos que tienden a dar un cuadro falso del estado de salud del paciente. La muestra enviada para un análisis completo, sea obtenida en cualquier momento del día o sea la primera micción de la mañana debe tener por lo menos un volumen de $15 \mathrm{ml}$. En los caos necesarios como en los niños pequeños, el procedimiento puede realizarse en volúmenes menores, pero es preferible de 10 a $15 \mathrm{ml}$ (Strasinger, Di Lorenzo\& King ,2010).

El uro cultivo es un método, que según el manual del centro Nacional de Diagnóstico y Referencia, CNDR (2004), la orina excretada en le riñón es estéril, salvo que dicho órgano este infectado. La orina sin contaminar de la vejiga también es normalmente estéril, sin embargo en la uretra existe una microbiota normal de modo que la orina expulsada en forma normal contiene una pequeña cantidad de bacterias. Debido a esto es necesario distinguir los microorganismos contaminantes de los de importancia etiológica. Solo el examen cuantitativo de la orina puede producir resultados significativos en cuanto a esta diferencia. El urocultivo se realiza para demostrar la presencia de un número significativo de bacterias, que usualmente se limitan a unos pocos microorganismos de crecimiento rápido. Las principales bacterias que afectan el sistema urinario son las enterobacterias y dentro de ellas Escherichia coli es la más frecuente. Un resultado será positivo con un solo tipo de bacteria con recuento mayor de 20,000 UFC x ml (unidades formadoras de colonias por mililitro de orina) y será negativo cuando no hubo crecimiento bacteriano (Pag.37).

El método de confirmación de IVU es el Urocultivo, sin embargo, sus resultados sólo están disponibles de 48 a 72 horas después de tomada la muestra, lo que limita su utilidad cuando hay urgencia terapéutica, y es más costoso que otras pruebas (Díaz, Gamazo y López,1999).

\subsection{Experiencias de investigación}

En Cuba en un estudio realizado en el Servicio de Nefrología del Hospital Pediátrico "William Soler" de la ciudad de La Habana, se reportó una incidencia de infección de las vías urinarias de 1.4\%. En un estudio realizado en el Hospital Pediátrico "General Milanés", de Bayamo, se obtuvo que la infección urinaria varía según el sexo y grupo de edades predominando el sexo masculino en los niños menores de 1 año.

En el Hospital Universidad del "Norte en Colombia" se realizó un estudio retrospectivo de las Infecciones de vías urinarias donde se demuestra que se produce con mayor frecuencia en el sexo femenino y la mayoría de ellas son causadas por Escherichia coli, para lo cual se procedió a la revisión de las historias clínicas de aquellos niños de entre 1 y 18 años que habían sido tratados en un hospital de pediatría y cuyo diagnóstico fue ITU o pielonefritis. En los Estados Unidos, alrededor de 4 millones de consultas médicas ambulatorias al año, son por IVU, lo que representa aproximadamente el 1 $\%$. En América Latina y el Caribe se ha estimado que al menos 8\% de las niñas y $2 \%$ 
de los niños tendrán IVU durante la infancia, y de ellos del 15 al 25\% presentan pielonefritis aguda, que los lleva a presentar insuficiencia renal a largo plazo (Salas,2012).

En Nicaragua se han realizado estudios relacionados con el comportamiento clínico y abordaje terapéutico en pacientes del Servicio de Nefrología con Glomerulonefritis en menores de 15 años en el Hospital "Manuel de Jesús Rivera" "La Mascota" en diciembre del 2004 encontrándose un foco infeccioso previo a su ingreso, siendo más frecuentes la localización faríngea y a nivel de la piel y con un comportamiento clínico clásico, siendo las complicaciones más frecuentes la insuficiencia renal aguda y crónica, trastornos electrolíticos e insuficiencia cardiaca (Gutiérrez y Ramírez, 2015).

El Hospital "Manuel de Jesús Rivera" La Mascota es uno de los centros con capacidad técnica y científica para atender problemas renales y de vías urinarias en niños de Nicaragua. Con la cooperación italiana se iniciaron proyectos que apoya principalmente en medicamentos, estudios especiales, procedimientos. En el año 2006 se formó la Asociación para Niños Nefropaticos (ANNEF) (Gutiérrez y Ramírez, 2015). En el Hospital Escuela "Asunción Juigalpa" no se han publicado estudios sobre el comportamiento de la infección de vías urinarias en niños por lo que esta investigación es un primer paso para posibles estudios sobre esta afección en el futuro.

\section{Metodología de la investigación}

\subsection{Enfoque de investigación}

El objetivo general de esta investigación se sintetiza en: "Infección de vías urinarias en niños menores de 12 años en una Comarca de Chontales" tomando en consideración factores asociados a las IVU en estos niños, por tales razones, se propone la metodología de la investigación correspondiente:

Todo estudio de investigación pretende responder a unos objetivos, a unos alcances, responder a unas preguntas o hipótesis. Todo lo concerniente al propósito del investigador deberá para obtener resultados significativos corresponderse con un adecuado nivel de investigación, lo cual hace referencia al grado de profundidad con que se aborda el fenómeno objeto de estudio.

Con la visión expuesta, el enfoque de esta investigación está fundamentado en los cimentos del paradigma positivista. Este paradigma ha guiado el tratamiento de los datos a través de la categorización y descripción de las propiedades, características y perfiles de las personas, grupos, comunidades, procesos y objetos que se han sometido a análisis (Hernández, Fernández, \& Baptista, 2010). El diseño de esta investigación es descriptivo, porque constituye una opción de investigación cuantitativa que trata de realizar descripciones precisas y muy cuidadosas respecto al fenómeno a investigar 
(Bisquerra, 2012, p. 197). De corte transversal porque se plantea en un único momento, es decir, en un periodo corto y determinado de tiempo.

\subsection{Participantes}

El estudio se llevó a cabo con una muestra de 30 niños menores de 12 años que habitan en la comarca San Francisco de el Gamalote, comunidad San Marcos, la cual colinda con las comunidades las Praderas, Cerro Margarita 1,2, Santana, Bizcocho y la Argentina, contando con una población total en las edades de estudio de 38 niños(a).

El Departamento de Chontales se encuentra en la zona central del territorio nicaragüense en un extenso paisaje de planicies y mesetas interrumpidas por elevaciones escarpadas como la Serranía de Amerrisque y los cerros de la Cordillera Chontaleña. Aunque poco conocida en materia turística, la región cuenta con numerosos atractivos naturales, arqueológicos, históricos, paisajísticos y de agro producción en toda su extensión. La oferta de servicios turísticos comienza a ser desarrollada gracias al apoyo de nuestro buen gobierno de unidad y reconciliación nacional y la infraestructura de hoteles y restaurantes es apta para la recepción de visitantes. La Comunidad en estudio "San Marcos" se encuentra a 24 Km de Juigalpa Chontales, está estimado que cuenta con 45 viviendas siendo un total de 38 niños como población de estudio, los cuales cumplen con criterios de inclusión en la investigación.

El 80\% son del sexo femenino, frente al $20 \%$ que son del sexo masculino, para el 100\% de los participantes. Es importante mencionar que la mayoría de los niños (a), nunca se habían realizado un análisis de orina hasta la fecha. Es pertinente resaltar e indicar que el tipo de muestreo que se ha utilizado ha sido el muestreo no probabilístico causal o accidental, que es aquel en el cual el investigador selecciona directa e intencionalmente la muestra, debido fundamentalmente a que tiene fácil acceso a la misma y es representativa de la población ( Ramírez, 2012 ).

\subsection{Instrumento de recogida de datos}

El instrumento utilizado para llevar a cabo esta investigación fue el cuestionario con preguntas cerradas. Para la aplicación del instrumento se procedió primero a revisar cómo había quedado definida la muestra y por ende, los elementos muestrales, es decir quiénes serían los sujetos objeto de estudio. Posteriormente se realizó una distribución del número de preguntas que se aplicarían por cada padre de familia y los procedimientos para su aplicación.

Prosiguiendo con el trabajo en esta fase que fue el trabajo de campo para la obtención de las muestras de orina, las cuales fueron utilizadas para el test, procesadas en el Laboratorio clínico privado y evaluar cuántos niños presentaron alteraciones celulares que orienta a una infección de vías Urinarias. 


\subsection{Procedimiento de administración y enfoque ético}

La administración del instrumento se realizó por parte del autor durante el segundo semestre del año académico 2019. Tenía un carácter anónimo y fue complementado por los sujetos participantes en presencia de los padres de familia que entregaron la muestra de orina recolectada. Con anterioridad a la toma de los datos, se obtuvo tanto el consentimiento libre e informado a los familiares de los niños, así como la autorización de los mismos para la realización de los exámenes.

\subsection{Análisis de datos}

Para procesar los datos obtenidos se ha aprovechado el proceso de automatización de datos mediante la aplicación del Statistical Package for the Social Sciences (SPSS) v.24, así también sirvió de apoyo el programa Open Epi versión 3, donde se calculó el intervalo de confianza con el que se trabajó que fue del $97 \%$ para un tamaño de muestral de 30 muestras.

\section{Resultados}

En el grupo de edad de las niñas(o) el grupo que se observó con mayor frecuencia fue la edad de 7 a 9 años con una frecuencia de 14 niños y niñas correspondiente a un $46.7 \%$ del total de los participantes, esto no significa que este grupo de edad sean los que tengan mayor incidencia de infección de vías urinarias porque según (Gonzalo, Mendez, \& Robles, 2013) ,la infección urinaria (IU) es un problema frecuente en los lactantes y niños, con una prevalencia aproximada del 2 al 5\%.

\begin{tabular}{|l|l|c|c|c|c|}
\hline \multicolumn{6}{|c|}{ Tabla 1. Edad de los niños y niñas que habitan en la vivienda } \\
\hline \multirow{3}{*}{ Edades } & Frecuencia & Porcentaje & Porcentaje válido & Porcentaje acumulado \\
\hline \multirow{5}{*}{ Válido } & $3-6$ años & 5 & 16.7 & 16.7 & 16.7 \\
\cline { 2 - 6 } & $7-9$ años & 14 & 46.7 & 46.7 & 63.3 \\
\cline { 2 - 6 } & $10-12$ años & 11 & 36.7 & 36.7 & 100.0 \\
\cline { 2 - 6 } & Total & 30 & 100.0 & 100.0 & \\
\hline
\end{tabular}

Fuente: Elaboración propia

Los niños con alteraciones celulares en las muestra de orina que orientan a una ivu ,en el presente estudio corresponden a un 10\% del total de muestras estudiadas, los que presentaron mayor positividad resultaron ser del sexo femenino en edades de 4 y 5 años, lo que se relaciona con lo que afirma Hellerstein(2012) que la infección del tracto urinario (ITU) es una de las infecciones bacterianas más frecuentes en pediatría, ya que el 8-10\% de las niñas y el 2-3\% de los niños tendrán una ITU sintomática antes de los siete años de edad, siendo más frecuente en varones en los primeros tres meses de vida y produciéndose un incremento progresivo con predominio de niñas a 
partir del año de vida, con alta probabilidad de recurrencia (>30\%) por reinfecciones distintos a la primera manifestación.

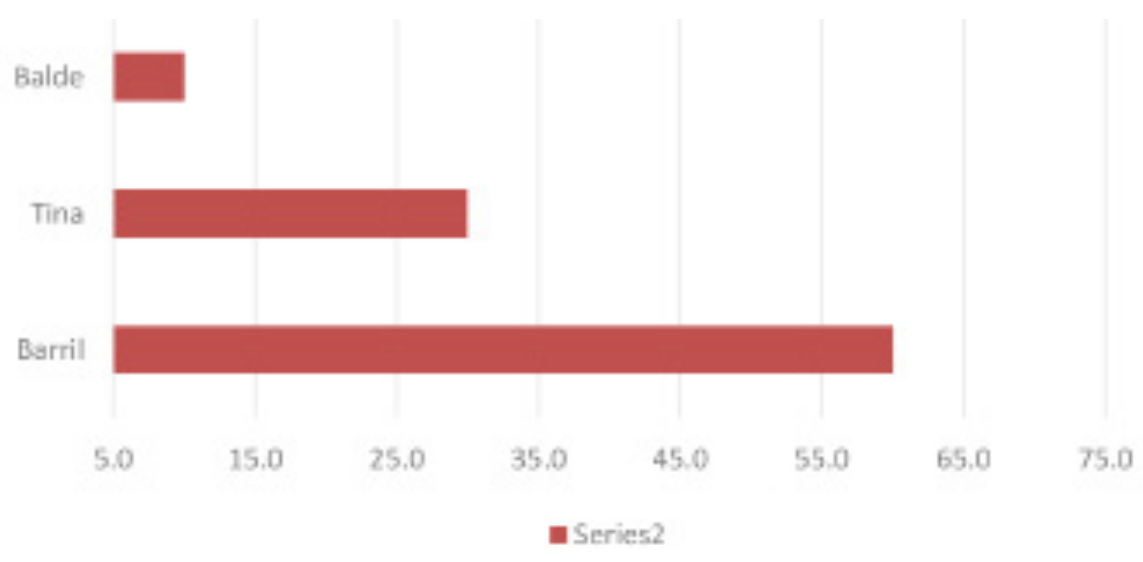

Figura 1: Lugar en la que los encuestados almacenan el agua de consumo

En esta Comarca el 99\% de la población en estudio gracias a la gestión del buen gobierno posee agua potable y la almacenan en barril por un periodo corto lo que se relaciona con el bajo porcentaje de personas con IVU y otras infecciones que según la Organización Mundial de la Salud (OMS) la falta de agua potable y saneamiento trae como consecuencia deshidratación y enfermedades diarreicas, sobre todo en la población Infantil.

Concerniente al análisis de laboratorio se realizó un examen general de Orina donde el 90\% de las muestras resultaron negativas para infeccion del tracto urinario y el 10\% presentaron alteraciones celulares sugerentes a IVU donde se encontró la presencia de bacteriuria, leucocitos mayores a 15 células lo que se relaciona con lo que expresan las literaturas en las definiciones de IVU.

Del 100\% de las muestras analizadas el 10\% resultaron con crecimiento bacteriano en el urocultivo, aislándose la bacteria Escherichia coli en todas las muestras, lo que concuerda con el manual práctico de microbiología, segunda edición donde afirma que la mayoría de las infecciones urinarias están producidas por bacterias, siendo algunas especies de la familia Enterobacteriaceae las que se aíslan con mayor frecuencia y dentro de ellas la E. coli, como resulto en estas muestras para esta investigación.

\section{Discusión y conclusiones}

El uso de Agua potable en esta comunidad es un factor fundamental lo que contribuye a la baja incidencia de IVU en esta población, cabe mencionar que esto no es una asociación entre el agua que consumen y la infección de vías urinarias por lo que la importancia radica en estarse haciendo controles, chequeos para evaluar el estado 
de salud de estos niños ya que no se descarta la posibilidad de adquirir infección en el futuro.

No se le realizó urocultivo a la mayoría de los niños, y a los que se les realizo el 10\% fueron positivos donde se encontró la bacteria Escherichia coli los cuales a nivel mundial son gérmenes más frecuentes. Se les realizo Examen General de Orina al 100\% de los participantes de los cuales solo el 10\% (3) presentaron alteraciones celulares sugerentes a IVU observándose leucocituria y Bacteriuria, siendo el urocultivo el Gold estándar.

Se ha detectado que en niñas con bacteriuria asintomática, la mayoría de ellas desarrollan infecciones persistentes o reinfecciones, por esta razón todo primer episodio de bacteriuria asintomática deberá ser evaluado para buscar factores predisponentes, igual que si fueran sintomáticas, por lo que esta investigación es relevante para un seguimiento a estas niñas ya que el grupo más afectado fueron del sexo femenino que resultaron con infecciones del tracto urinario y de igual manera se sugiere un mismo seguimiento a los niños que presentaron negatividad en el estudio porque podrían desarrollar la infeccion en el futuro debido a los factores predisponentes a los que están expuestos como es zona lluviosa con mucho lodo en el invierno, la cultura del lavado de manos, higiene personal, tomar agua en algún Rio por la cultura de trabajo de los padres, por lo que la identificación precoz y precisa del niño(a) con infección urinaria es de capital importancia para reducir la morbilidad y las secuelas asociadas.

El método diagnóstico utilizado ha de ser lo más sensible y específico posible, evitando así el infra diagnóstico, que conlleva al retraso en la terapia con una posible progresión del daño renal debido a que las manifestaciones clínicas de la IVU varían según la edad. En los últimos años se ha producido un incremento global de la resistencia a antimicrobianos, principalmente en bacilos Gram-negativos debido a que en la mayoría de las ocasiones el tratamiento antibiótico se instaura de forma empírica, por lo que se recomienda la realización de análisis previos.

\section{Lista de referencias}

Alvarez, E. (2013). Comportamiento de la enfermedad renal cronica. Hospital Manuel de Jesus Rivera.

Avila, J. M., \& Espinoza, L. (2008). Marcadores Clinicos de Enfermedad renal. Asociacion española de pediatria .

Amaia R, Raquel M, Ma Concepción D (2002) . FIR de Análisis Clínicos del Hospital de Navarra. Disponible en: http://www.cfnavarra.es/salud/PUBLICACIONES/ 
Libro\%20electronico\%20de\%2otemas\%20de\%2oUrgencia/24.Miscelanea/ Analisis\%2ode\%2oorina.pdf

Bisquerra, R. (2012). Metodología de la investigación educativa. Editorial la Muralla, S.A.

Cruz, R. (2007). Infeccion del tracto urinario en pediatria. La Paz .

Cruz, R., Saballos, M., \& Gurachi, M. (2007). INFECCION DEL TRACTO URINARIO EN PEDIATRIA. LA PAZ .

Díaz, R. Gamazo, C \& López G.(1999). Manual Práctico de Microbiología. Pamplona Segunda edición.

De la Cruz J. Lozano J. Figueroa J. Morales Y. Manejo de la Infección Urinaria en niños entre dos meses y cinco años. Guías de Pediatría Práctica basadas en la evidencia. Cap 15. Ed. Panamericano. Bogotá, 2003, 191-208.

Gonzalez, J., D., \& Rodriguez, L. . (2014). Infeccion de vias urinarias en la infancia. Complejo Hospitalario Universitario de Cartagena, Unidad de Nefrologia Pediatrica.

Gutiérrez, M. \& Ramírez, M.(2015). Comportamiento de las infecciones del tracto Urinario en Pacientes ingresados en la sala de Miscelaneo de pediatría en el Hospital Escuela Carlos Roberto Huembes, Enero2014-Diciebre 2015.

Grace \& José A. (2014). Utilidad de la Tinción de Gram en el Diagnóstico y tratamiento oportuno de la infeccion de vías urinarias en menores de cinco años: Estudio Realizado en el Hospital del Niño Dr. Francisco Ycaza Bustamante de Marzo -Agosto 2014.

Hernández, R. Fernández, C.,\& Baptista. (2010). Metodología de la investigación (Quinta ed.)México: Mc Graw Hill.

Hellerstein S. Acute urinary tract infection: evaluation and treatment. Curr Opin Pediatr. 2012; 18: 134-8.

MINSA. (2009). Guia para el diagnostico y tratamiento de las enfermedades renales en niños, Normativa 025-104. Normativa Minsa .

MINSA,CNDR(2004). Manual de Procedimientos de Bacteriologia Medica. Complejo Nacional de Salud Dra Concepción Palacios. Managua apartado Postal 107.

Ramírez F.(2012). Infección de vías urinarias en pacientes pediátricos. Monografía. Instituto Mexicano de Seguridad Social de Veracruz, México. 
Laurine, G.(1987). Análisis de Orina. México editorial Médica Panamericana S.A.

Salas de la C. Paulina (2012). Actualización en el diagnóstico y manejo de la infección urinaria en pediatría. Revista Chilena Pediatría. Vol. 83. Núm. 3.

Strasinger,Schau, D \& Susan, K.(2010). Análisis de orina y de los líquidos corporales .Buenos Aires Argentina, Editorial Medica Panamericana S.A.

Sociedad Española de Enfermedades Infecciosas y Microbiología Clínica. Madrid: SEIMC; 2002 [acceso 20 de abril de 2005]. Procedimientos en MicrobiologíaClínica. Disponible en: http://www.seimc.org/protocolos/microbiologia/. 